\title{
Research on Rolling Motion Mode of a Swath unmanned craft with monitoring function
}

\author{
Guo Hanhui, Yu Yongqiang, Yang Songlin, Mei Jinya, Gu Kai
}

\begin{abstract}
In this paper, a swath unmanned craft is taken as the research object, a series of static roll attenuation tests were carried out under different draft and different initial roll angles. By changing the composition of the restoring moment and damping, 3 mathematical models of roll attenuation motion system identification were established. And based on system identification theory and a variety of optimization algorithms programming ideas, the identification and analysis of the rolling data of unmanned craft were carried out, and a better mathematical model of rolling motion was obtained by identification and calculation, and the variation of identification parameters under different draught and inclination angles was compared.
\end{abstract}

Index Terms - Swath unmanned craft; Ship model test; System identification; Roll motion mode.

\section{INTRODUCTION}

Appeared in the 1950s, unmanned surface vessel have a great development so far.Through the continuous efforts of relevant researchers, remarkable results have been achieved on the study of the performance optimization of unmanned surface vessel.All kinds of optimization algorithms are applied to the optimization calculation of unmanned surface vessel, and the optimization quality and efficiency are improved continuously. At present, there are A large number of available date of Full-scale and ship model was obtained through the researches on the hydrodynamic performance of catamaran, especially the resistance performance.For example,Wang Chengyi summarized the influencing rule of the ship type parameters on the catamaran resistance is summarize. Zou Zaojian developed an swatch resistance prediction system based on Rankie method of source.Chen jing developed the procedure for predicting wave resistance of Catamaran by using the improved method of Dawson.Li wei et al. established the formula for estimating residual resistance coefficient and wet area through regression analysis.

As the extension of the national natural science foundation project "Comprehensive Optimization Model and Method for the Performance of High-speed Unmanned Surface Vehicle",our research need a large amounts of experimental data.Therefore, it is very important to study the roll motion

mode of the a Swath unmanned craft and to forecast the roll motion.And model test is one of the effective methods to predict roll motion.

Guo Hanhui, Yu Yongqiang, Yang Songlin, Mei Jinya, Gu Kai, School of Naval Architecture \& Ocean Engineering, Jiangsu University of Science and Technology, Zhenjiang, Jiangsu, China
In this paper, the hydrostatic rolling motion model of a swath unmanned craft was tested and analyzed. According to the principle of dynamic balance in rolling, a mathematical model of linear and nonlinear rolling attenuation motion model was established, and the relevant design variables and objective functions were determined respectively.C\# language was used to rewrite the system identification software including genetic algorithm and particle swarm algorithm,and the roll test data were identified and analyzed by identification program.It can be known that the relative error between the test value and the forecast value was small, and the fitting degree was preferable.Namely, the system identification method was proved to be reliable.

\section{MODEL DESIGN}

As the unmanned surface vessel mainly targets at the offshore and offshore meteorological monitoring functions, it needs to be equipped with a variety of monitoring equipment.A relatively stable working environment is needed to ensure the stability and reliability of the monitoring data. Therefore, its wave resistance function is relatively more important.

The optimization results of main dimensions of the Swath unmanned craft is shown in table 2.1.

Table 2.1 The optimization results of main dimensions of the swath unmanned craft.

\begin{tabular}{lll}
\hline Design variable & Symbol & Value \\
\hline Length & $L$ & 1.26 \\
Demihull width & $B$ & 0.6 \\
Depth & $D$ & 0.48 \\
Draft & $T$ & 0.21 \\
Displacement & $\Delta$ & 60 \\
Longitudinal & $S_{1}$ & 0.06 \\
spacing & $S_{2}$ & 0.05 \\
Rib intervals & $V$ & 5 \\
Velocity & $c_{0}$ & 0.45 \\
Hull separation & &
\end{tabular}

The swath unmanned craft consists of three parts: two submarines that are located far below the waterline, a spacious box-type connection bridge and a segment pillar that connects the upper boat body and the lower submarines. The basic design idea is to move most of the buoyancy structure part of the swath unmanned craft to a certain depth far from the wave disturbance. By reducing the surface area of the 
waterline, the wave force and disturbance torque on the boat body can be reduced, thus improving the wave resistance of the unmanned surface vessel.

The 3D modeling diagram of the trial unmanned craft is shown in the figure.
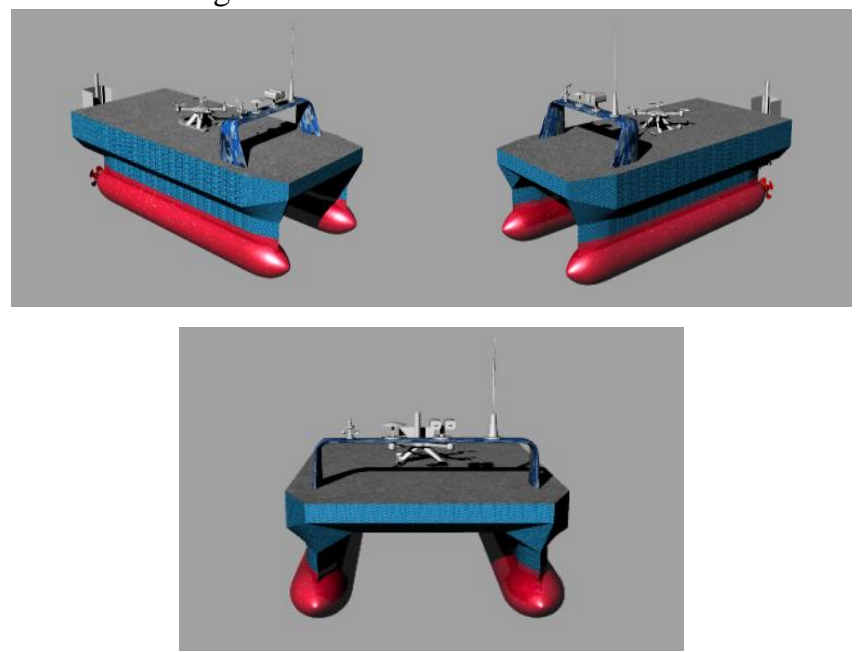

Fig.2.1.The 3D modeling diagram of the trial unmanned craft

\section{SCHEME FOR PITCH TEST OF CRAFT MODEL}

\section{A. Methods of procedure}

The experiment was carried out at the towing tank of Jiangsu University of Science and Technology. The towing tank is 100 meters long, 6 meters wide, and the largest depth of water is 2 meters. In order to obtain the best roll free attenuation data, the transverse direction of the model of the catamaran was perpendicular to the long side of the pool during the experiment. At the same time, in order to reduce the effect of the wall of the tank on the rolling motion of the catamaran model, wave attenuation devices were placed at both ends of the tank to absorb the waves generated during the rolling process. In this paper, the attenuation law of the trial unmanned craft was determined by measuring the change of the rolling angle of the trial unmanned craft in the process of free attenuation in still water.

(1)We prepared for trial the instrument including test model , MTi-G inertial measuring instrument (six degrees of freedom motion of measurable craft), data transmission line and computer;

(2)In order to reduce the effect of the wall of the tank,the craft model was placed in the center of the pool, and the craft model was adjusted by loading weights to make it at the state of zero trim;

(3)The MTi-G inertial measurement unit was placed horizontally on the center of gravity of the craft's model and connected to the equipment with data lines;

(4)When the model was at the state of zero trim, the roll angle of the craft model was read by MTi-G software. By adjusting the horizontal position of the MTi-G, the initial roll angle of the software was guaranteed to be between 0.2 degrees;

(5)When craft model was stable, the external force was applied and click to record the data. At the same time, the craft mode is allowed to freely pitching. When the model was stable again, the data acquisition was stopped;
(6)In the process of repeating (4) - (5), the initial angle of rolling was changed. The initial angle of rolling was four groups of designed draft, including 3.5,7,15 degrees.

(7)The design draft roll test was carried out by adding or

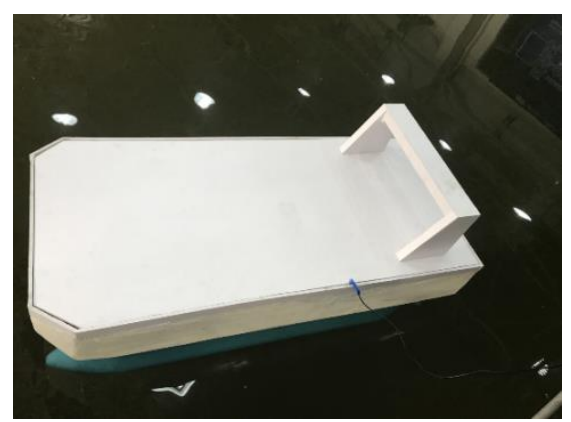

reducing ballast by 1.1 and 0.9 times, repeated steps (4) - (6). Fig.3.1 roll test of craft model

\section{B. Identification equation and mathematical model}

According to the equilibrium equation of hydrostatic moment :

$M(\ddot{\varphi})+M(\dot{\varphi})+M(\varphi)=0$

We need to modify and transform the moment term in the balance equation to find the roll equation suitable for the craft model in this paper.

Equation 1:

$$
\begin{gathered}
\ddot{\phi}+2 N \dot{\phi} / I_{x x}^{\prime}+W|\dot{\phi}| \dot{\phi} / I_{x x}^{\prime}+x \phi^{3} / I_{x x}^{\prime}+ \\
C_{1} / I_{x x}^{\prime} \phi^{3}+C_{2} / I_{x x}^{\prime} \phi^{2}+C_{3} / I_{x x}^{\prime} \phi=0
\end{gathered}
$$

Select design variables: $I_{x x}^{\prime}, N, W, x, C_{1}, C_{2}, C_{3}$, the range of design variables value :

$I_{x x}^{\prime} \in[0,0.1], N \in[0,1], W \in[0,1], x \in[0,10]$,

$h \in[0,10], C_{1} \in[0,10], C_{2} \in[0,10], C_{3} \in[0,10]$

Equation 2:

$$
\begin{gathered}
\ddot{\phi}+2 N \dot{\phi} / I_{x x}^{\prime}+W|\dot{\phi}| \dot{\phi} / I_{x x}^{\prime}+x \phi^{3} / I_{x x}^{\prime} \\
+D h \phi / I_{x x}^{\prime}=0
\end{gathered}
$$

Select design variables : $I_{x x}^{\prime}, N, W, x, h$, the range of design variables value :

$I_{x x}^{\prime} \in[0,0.1], N \in[0,1], W \in[0,1]$,

$$
x \in[0,10], h \in[0,10]
$$

Equation 3:

$$
\begin{gathered}
\ddot{\phi}+2 N \dot{\phi} / I_{x x}^{\prime}+W|\dot{\phi}| \dot{\phi} / I_{x x}^{\prime}+x \phi^{3} / I_{x x}^{\prime}+ \\
C_{1} / I_{x x}^{\prime}(\sin \phi)^{2}+C_{2} / I_{x x}^{\prime} \sin \phi=0
\end{gathered}
$$

Select design variables :

$$
I_{X X}^{\prime}, N, W, x, C_{1}, C_{2} \text {, the range of }
$$

design variables value :

$I_{x x}^{\prime} \in[0,0.1], N \in[0,1], W \in[0,1], x \in[0,10]$,

$h \in[0,10], C_{1} \in[0,10], C_{2} \in[0,10]$

Where, $\phi$ means the roll angle; $\dot{\phi}$ represents the angular velocity of roll; $\bar{\phi}$ represents

the angular acceleration of the roll; $I_{x x}^{\prime}$ represents the total inertia moment; $N$ repr-esents the coefficient of linear 
damping torque; $W, x$ representation of nonlinear damping moment coefficient; $C_{1}, C_{2}$ representation of nonlinear righting moment coefficient; $C_{3}$ re-presents the coefficient of linear righting moment.

The prediction of the pitch angular velocity at the $\kappa+1$ moment is shown below:

$$
\varepsilon_{k+1}=\dot{\phi}_{k+1}^{\prime}-\dot{\phi}_{k+1}
$$

Which is: $\dot{\phi}_{K+1}$ is the measured value of the angular velocity of $\mathrm{K}+1$ time; $\dot{\phi}_{K+1}^{\prime}$ is the value obtained by the angular velocity identification of $K+1$ times.

Then the objective function was selected as shown in equation 3.6. The smaller the objective function value is, the better the formula imitative effect is.

$$
F(x)=\sqrt{1 / N \sum_{k=1}^{N}\left(\dot{\varphi}_{K+1}^{\prime}-\dot{\varphi}_{K+1}\right)^{2}}
$$

Which is: $\mathrm{N}$ represents the Total number of test points.

\section{ROLLING IDENTIFICATION OPTIMIZATION CALCULATION}

\section{A. Analyses of the results of the roll test}

The hydrostatic monitoring of the swath unmanned craft in the water area was completed. During the test, each inception roll angle was tested three times, and the best set of test data was selected as the effective data. Due to the human factors, there is a certain error in the test. Fig 4.1 shows the inception roll angle of $3^{\circ}$, the draft is 0.9 times the design draft, the design draft, and the 1.1 times the design draft. The roll angular velocity decay is compounded in the figure, so the test data of roll is available.

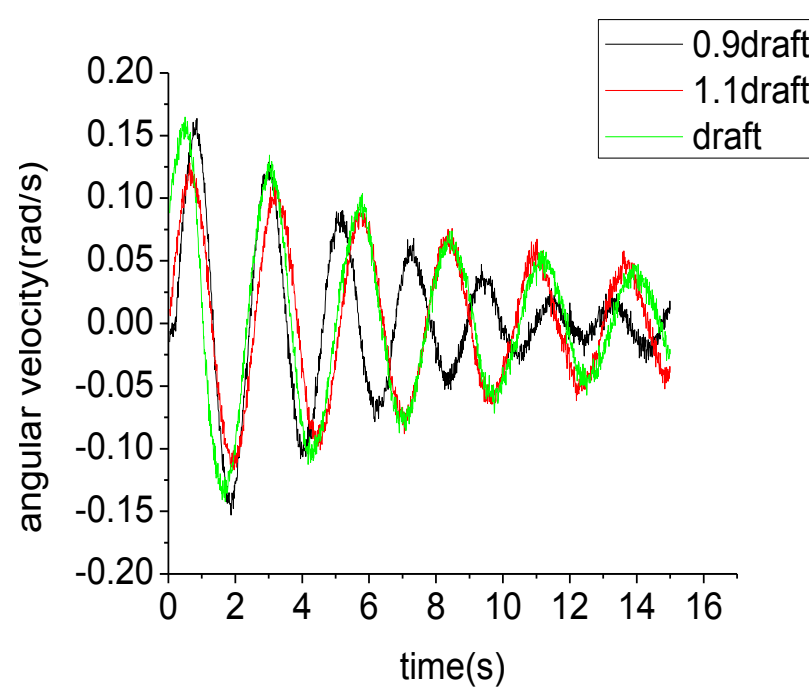

Fig.4.1 Rolling angular velocity decay curve under different draft and rolling inception angle of $6^{\circ}$

As shown in Fig 4.1, when the three kinds of draft and the inception roll angle are $3^{\circ}$. With the increase of draught, the peak value of rolling angular velocity increases, the rolling period decreases.

\section{B. Rolling identification calculation scheme}

Design: Identification optimization algorithm selection improved genetic algorithm.

Genetic algorithm was selected to set the basic parameters as: optimization algebra was 2000, population size was 200, genetic factor was 0.05 , crossover probability was 0.8 , and mutation probability was 0.15 .

The identification and calculation of three kinds of draft and different initial roll angles were carried out with the identification system of three different roll mathematical models. The identification results are shown in table 4.1-4.3.

Table 4.1 The calculation results of the target function when the draft is 0.9 times the design draft

\begin{tabular}{cccc}
\hline $\begin{array}{c}\text { Objective } \\
\text { function } \\
\text { value }\end{array}$ & Equation 1 & Equation 2 & Equation 3 \\
\hline $3^{\circ}$ & 0.006926387 & 0.007072374 & 0.00692628 \\
$5^{\circ}$ & 0.007733045 & 0.007543259 & 0.007600843 \\
$7^{\circ}$ & 0.007435132 & 0.008013601 & 0.007447981 \\
$15^{\circ}$ & 0.007258277 & 0.007549649 & 0.007278172 \\
\hline
\end{tabular}

Table.4.2 The calculation results of the target function when the draft is the design draft

\begin{tabular}{cccc}
\hline $\begin{array}{c}\text { Objective } \\
\text { function } \\
\text { value }\end{array}$ & Equation 1 & Equation 2 & Equation 3 \\
\hline $3^{\circ}$ & 0.007212248 & 0.007311815 & $0.007212803 \cdot$ \\
$5^{\circ}$ & 0.007094175 & 0.007381487 & 0.007095983 \\
$7^{\circ}$ & 0.007524677 & 0.00805055 & 0.00754228 \\
$15^{\circ}$ & 0.017812411 & 0.016426685 & 0.01654142 \\
\hline
\end{tabular}

Table.4.3The calculation results of the target function when the draft is 1.1 times the design draft

\begin{tabular}{cccc}
\hline $\begin{array}{c}\text { Objective } \\
\text { function } \\
\text { value }\end{array}$ & Equation 1 & Equation 2 & Equation 3 \\
\hline $3^{\circ}$ & 0.007416509 & 0.007528412 & 0.007417618 \\
$5^{\circ}$ & 0.007736636 & 0.00792392 & 0.007741602 \\
$7^{\circ}$ & 0.040777705 & 0.040878904 & 0.040777683 \\
$15^{\circ}$ & 0.018117151 & 0.018893724 & 0.018199396 \\
\hline
\end{tabular}

Compared to the initial roll Angle of $3^{\circ}, 5^{\circ}, 7^{\circ}, 15^{\circ}$, the result is shown in Fig 4.2. 


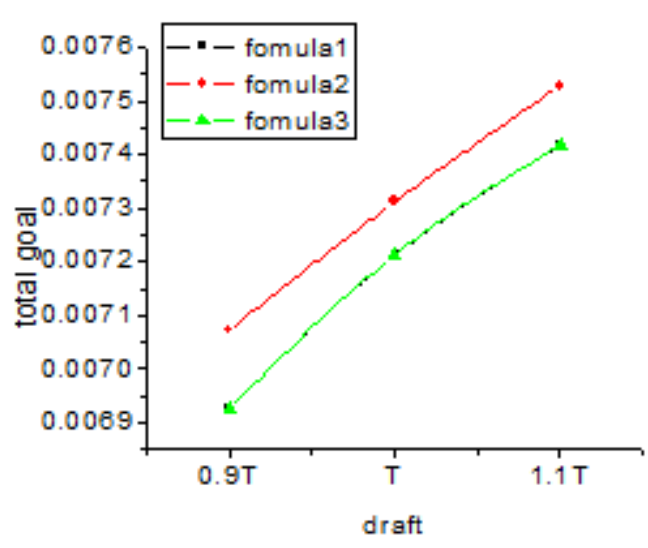

(a) $3^{\circ}$

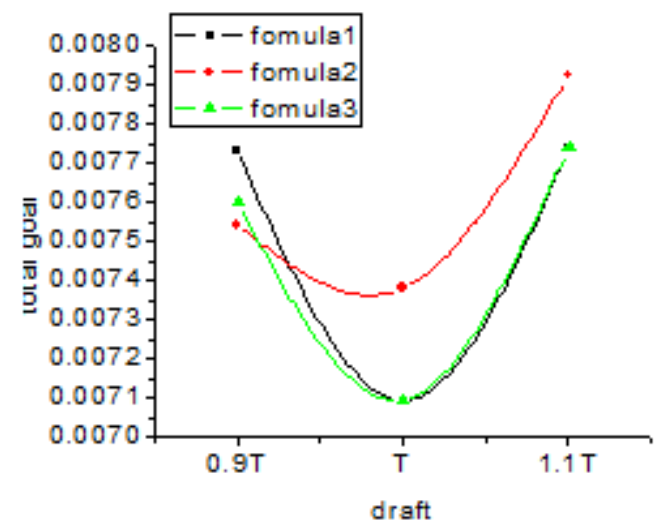

(b) $5^{\circ}$

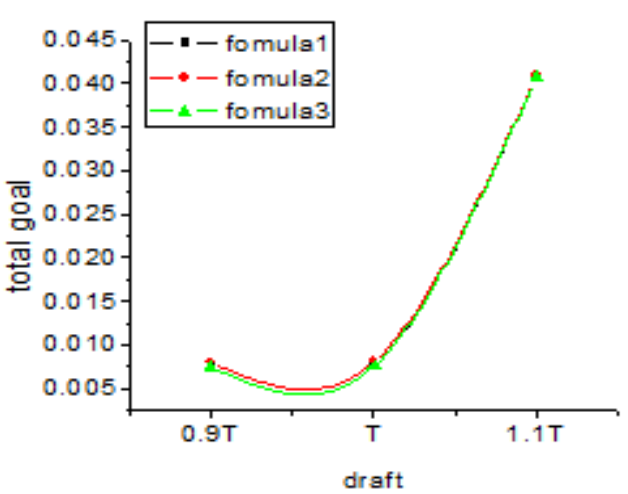

(c) $7^{\circ}$

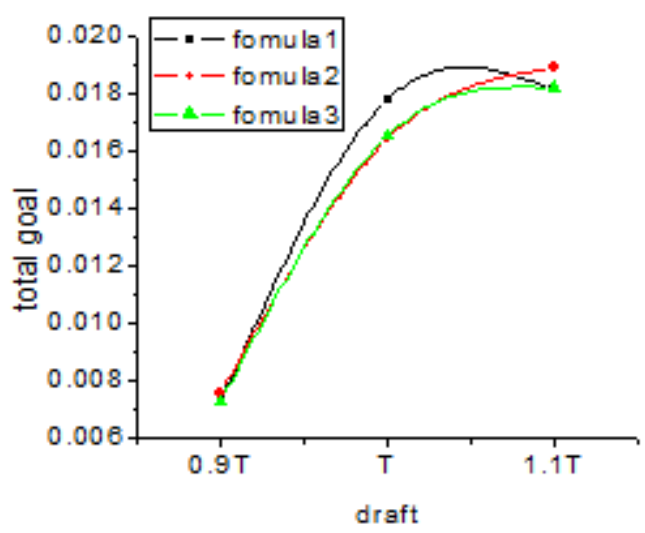

(d) $15^{\circ}$

Fig.4.2 Calculation results of three identification formulas under four different initial roll Angle conditions
By comparing the above objective function values, it is found that the objective function value of equation 3 is the minimum under the conditions of three different draught and four different initial roll angles, indicating that formula 3 has the best fitting effect. Taking pitch angle 5 under design draft as an example, the objective function values is shown in table 4.4:

Table.4.4 Optimized values for each design variable on the formula 3

\begin{tabular}{|l|l|l|l|}
\hline design variables & $\begin{array}{l}\text { lower } \\
\text { limit }\end{array}$ & $\begin{array}{l}\text { upper } \\
\text { limit }\end{array}$ & $\begin{array}{l}\text { optimized } \\
\text { values }\end{array}$ \\
\hline $\begin{array}{l}\text { Total moment of } \\
\text { inertia } I x\end{array}$ & 0 & 0.1 & 0.080320655 \\
\hline $\begin{array}{l}\text { Rolling linear } \\
\text { damping moment } \\
\text { coefficient } N x\end{array}$ & 0 & 1 & 0.000247681 \\
\hline $\begin{array}{l}\text { Rolling nonlinear } \\
\text { damping moment } \\
\text { coefficient } W\end{array}$ & 0 & 1 & 0.981940173 \\
\hline $\begin{array}{l}\text { Rolling nonlinear } \\
\text { damping moment } \\
\text { coefficient } x\end{array}$ & 0 & 10 & 2.615040557 \\
\hline $\begin{array}{l}\text { nonlinear righting } \\
\text { moment } \\
\text { coefficient } C_{l}\end{array}$ & 0 & 10 & 3.663245158 \\
\hline $\begin{array}{l}\text { nonlinear righting } \\
\text { moment } \\
\text { coefficient } C_{2}\end{array}$ & 0 & 10 & 0.498282369 \\
\hline
\end{tabular}

$$
\begin{gathered}
\ddot{\phi}+2 \times 0.000247681 \dot{\phi} / 0.080320655+ \\
0.981940173|\dot{\phi}| \dot{\phi} / 0.080320655+ \\
2.615040557 \phi^{3} / 0.080320655+ \\
3.663245158 / I_{x x}^{\prime}(\sin \phi)^{2}+ \\
0.498282369 / I_{x x}^{\prime} \sin \phi=0
\end{gathered}
$$

The rolling motion model is as follows:

In order to analyze the error between the experimental value and the fitted value, the angular velocity test value of the design draught and the inception roll angle of $3^{\circ}$ and the fitted value identified by Equation 3 are placed in the same coordinate system, as shown in Fig 4.3 :

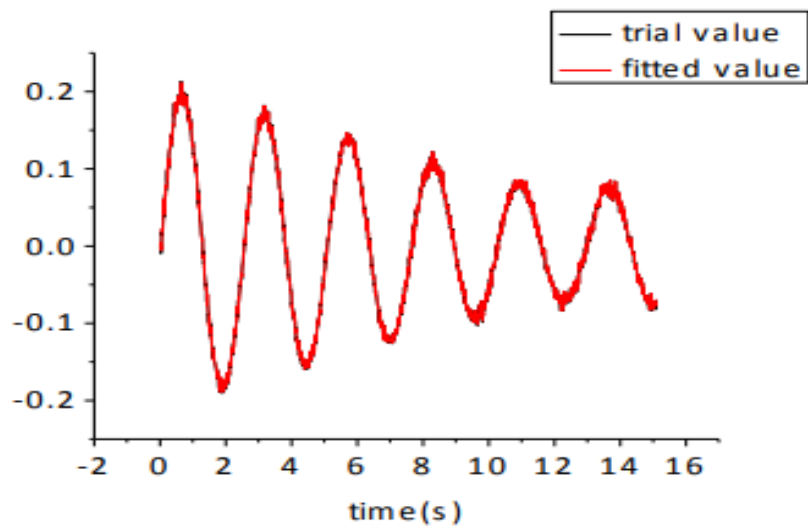

Fig.4.3 Test angular velocity and identification angular velocity fitting curve 
It can be seen from the above figure that the experimental angular velocity and the identification angular velocity have good imitative effects, which can prove the reliability and stability of the equation 3 in the identification software model. Therefore, the identification software can predict the roll angular velocity at the next moment.

The total inertia torque Ix, damping torque coefficient $\mathrm{Nx}$, square damping torque coefficient $\mathrm{W}$, cubic damping torque coefficient $\mathrm{x}$ and restoring torque coefficients under each condition obtained by identifying and calculating nine groups of rolling test data. Among them, the curves of the design variables with the inception roll angle under three kinds of draught are shown in Fig 4.4-4.6.
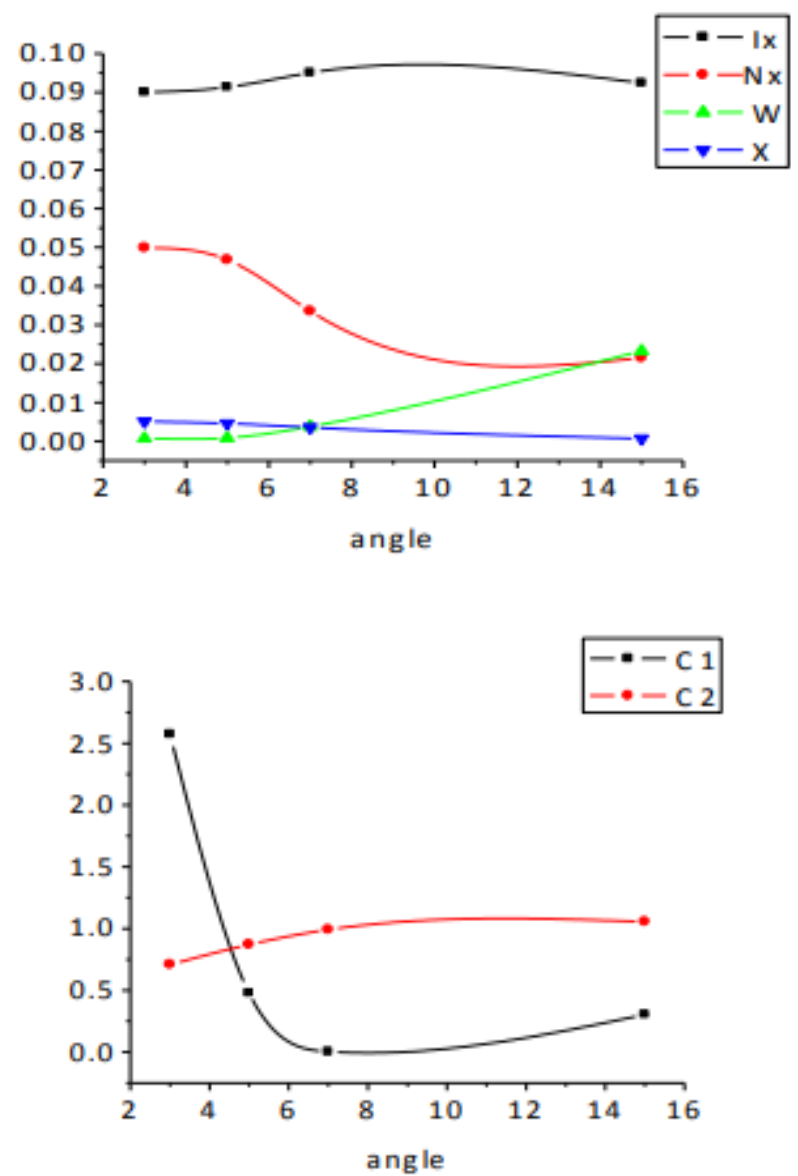

Fig. 4.4 The curves of moment coefficients change with the initial pitch Angle under 0.9 times the design draft

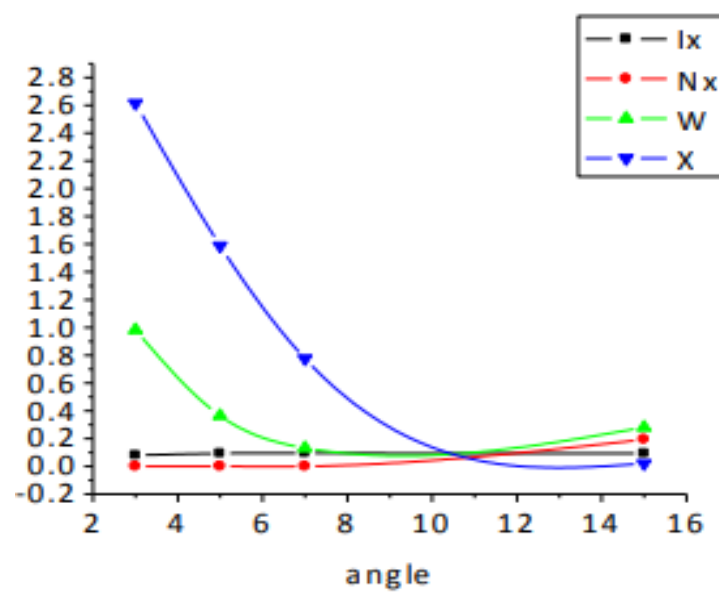

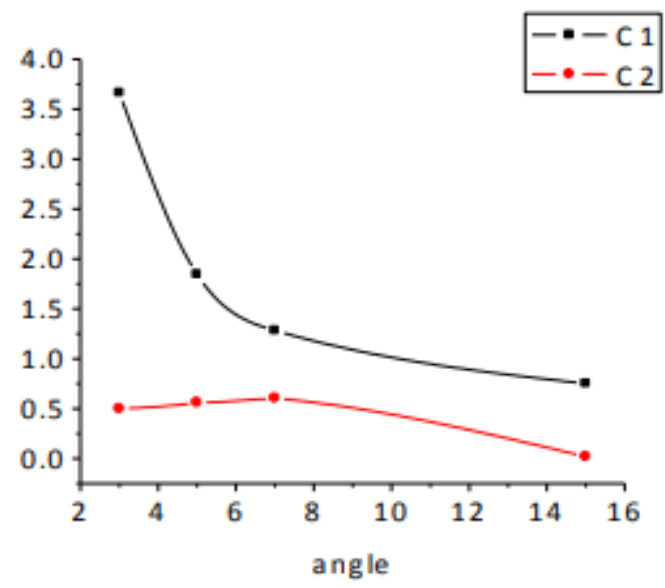

Fig.4.5 The curves of moment coefficients change with the initial pitch Angle under the design draft
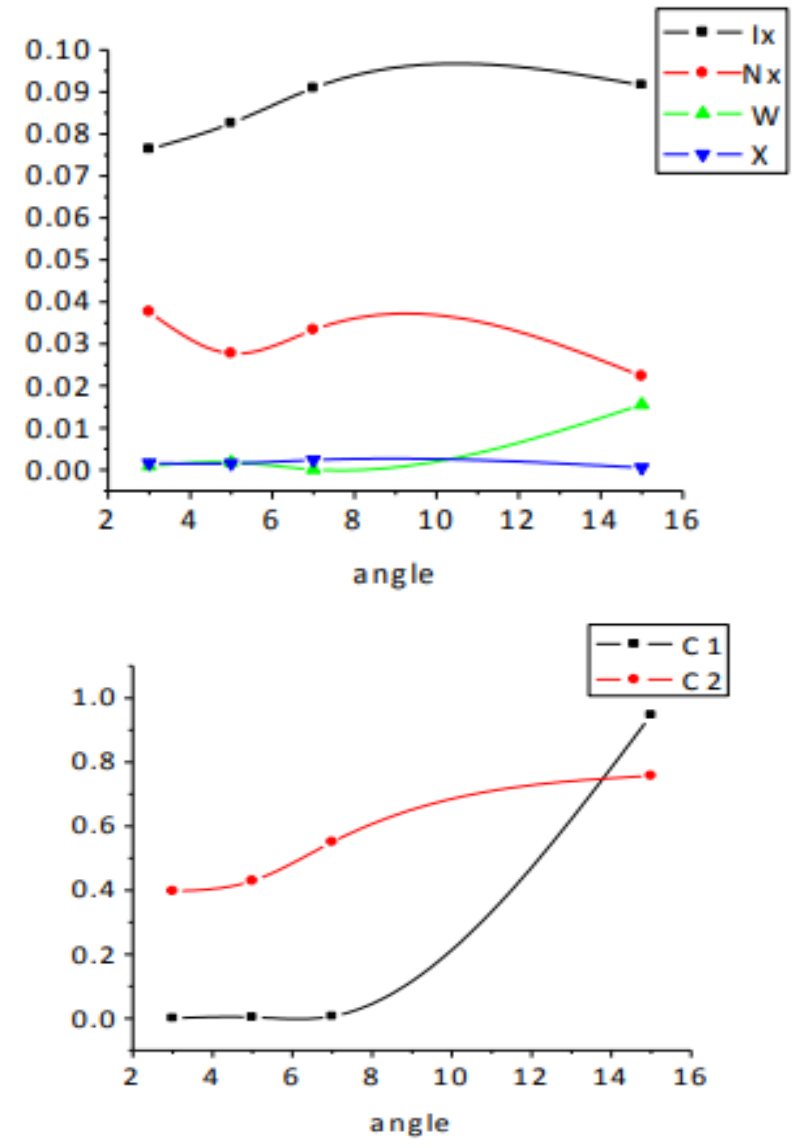

Fig. 4.6 The curves of moment coefficients change with the initial pitch Angle under 1.1 times the design draft

It can be known from Fig. 4.4-4.6 that the values of the torque coefficients vary with the draught and the inception roll angle. In the case of 0.9 times the design draft, the hull rolling total torque of inertia Ix has a great influence on the equation, and the cubic damping torque coefficient $X$ has little effect on the equation. However, they do not change significantly with the initial roll Angle. The linear damping moment coefficient $N_{x}$ decreases with the increase of the initial roll angle, while the square damping torque coefficient $W$ increases. When the initial roll Angle is less than $6^{\circ}$, the nonlinear righting moment coefficient $C_{1}$ decreases rapidly with the increase of initial rolling Angle. However, the nonlinear righting moment 
coefficient $C_{2}$ is less affected by the change of initial roll Angle.

In the case of design draft, the hull rolling total torque of inertia Ix and the linear damping moment coefficient $N_{x}$ do not change significantly with the initial roll Angle. When the initial roll Angle is less than $6^{\circ}$, the nonlinear righting moment coefficient $C_{1}$ increases with the increase of initial rolling Angle. However, the nonlinear righting moment coefficient $C_{2}$ is less affected by the change of initial roll Angle. The nonlinear righting moment coefficient $C_{1}$ is much bigger than the nonlinear righting moment coefficient $C_{2}$, which means that the trigonometric second power has more influence on the equation than the first power.

In the case of 1.1 times the design draft, the hull rolling total torque of inertia Ix, the linear damping moment coefficient $N_{x}$, the square damping torque coefficient $W$ and the cubic damping torque coefficient $X$ do not change significantly with the initial roll Angle. On the other hand, the nonlinear righting moment coefficient $C_{1}$ and $C_{2}$ increase with the increase of initial roll Angle.

\section{CONCLUSION}

In this paper, model experiment and system identification method were used to study the rolling-attenuation motion mode of a swath unmanned craft in still water state. The mathematical model which was most suitable for the ship model in the paper and could accurately describe the pitch motion process in 12 working conditions was found through the calculation of identification program. The correct value of each moment coefficient was obtained, the law of each moment coefficient changing with the Angle of draft and roll was found, and the correctness of the system identification software was verified. It can be concluded that the system identification software can predict the future navigation parameters and motion posture of unmanned boat, providing reference for further study on the pitching motion of small waterline catamaran.

All in all, our roll test provides the following projects: National Natural Science Foundation of China Comprehensive optimization model and method for the performance of high speed USV and National Natural Science Foundation of China A preliminary study on the ship type of high speed unmanned combat platform on the surface with the relevant experimental data, and it provides a reference for the further study of the roll motion of the swath unmanned craft.

\section{REFERENCE}

[1] Yousefi R, Shafaghat R, Shakeri M. Hydrodynamic analysis techniques for high-speed planing hulls[J]. Applied Ocean Research, 2013, 42(4):105-113.

[2] A. Lavrov, J.M. Rodrigues, J.F.M. Gadelho, C. Guedes Soares, Calculation of hydrodynamic coefficients of ship sections in roll motion using Navier-Stokes equations[J]. Ocean Engineering, Volume 133, 2017, Pages 36-46, ISSN 0029-8018.

[3] Jian-Chuan Yin, Zao-Jian Zou, Feng Xu, Ni-Ni Wang, Online ship roll motion prediction based on grey sequential extreme learning machine[J]. Neurocomputing, Volume 129, 2014, Pages 168-174, ISSN 0925-2312.
[4] Abhilash Somayajula, Jeffrey Falzarano, Application of advanced system identification technique to extract roll damping from model tests in order to accurately predict roll motions[J]. Applied Ocean Research, Volume 67, September 2017, Pages 125-135, ISSN 0141-1187.

[5] Falzarano J, Somayajula A, Seah R. An overview of the prediction methods for roll damping of ships[J]. 2015, 5(2):55-76.

[6] D. Sathyaseelan, G. Hariharan, K. Kannan, Parameter identification for nonlinear damping coefficient from large-amplitude ship roll motion using wavelets, Beni-Suef University Journal of Basic and Applied Sciences, Volume 6, Issue 2, 2017, Pages 138-144, ISSN 2314-8535.

[7] Chan H S Y, Xu Z, Huang W L. Estimation of nonlinear damping coefficients from large-amplitude ship rolling motions[J]. Applied Ocean Research, 1995, 17(4):217-224.

[8] Jian-chuan Yin, Zao-jian Zou, Feng Xu, On-line prediction of ship roll motion during maneuvering using sequential learning RBF neuralnetworks, Ocean Engineering, Volume 61, 2013, Pages 139-147, ISSN 0029-8018.

[9] A. Somayajula, J. Falzarano. Estimation of roll motion parameters using R-MISO system identification technique. J.S. Chung, M. Muskulus, T. Kokkinis, A.M. Wang (Eds.), 26th International Offshore and Polar Engineering (ISOPE 2016) Conference, vol. 3: Rhodes (Rodos), International Society of Offshore and Polar Engineers (ISOPE), Greece (2016), pp. 568-574.

[10] Sun Xiaoshuai, Yao Chaobang, Ye Qing. Numerical and Experimental Study on Rolling Damping Characteristics of Small Waterplane Catamaran $[\mathrm{J}]$. Journal of National University of Defense Technology, 2017(6)

[11] Zhang Yulong, Li Hongxia, Wang Wenhua, Zhen Xingwei. Research on Determination Method of Ship Rolling Damping [J].China Shipbuilding, 2015, 56(S1):155-160.

[12] Liu S, Papanikolaou A. Prediction of parametric rolling of ships in single frequency regular and triple frequency group waves $[\mathrm{J}]$. Ocean Engineering, 2016, 120:274-280.

[13] Jovanoski Z, Robinson G. Ship Stability and Parametric Rolling [J]. Australasian Journal of Engineering Education, 2009, 15(2):43-50.

[14] Kawahara Y, Maekawa K, Ikeda Y. A Simple Prediction Formula of Roll Damping of Conventional Cargo Ships on the Basis of Ikeda' s Method and Its Limitation[M]// Contemporary Ideas on Ship Stability and Capsizing in Waves. Springer Netherlands, 2011:201-210. 